Original Contribution

\title{
DOES INTERMITTENT PNEUMATIC COMPRESSIONAFFECT TIME TO SURGERY IN MALLEOLAR FRACTRES?
}

\author{
T. Al-Sadek ${ }^{1 *}$, D. Niklev ${ }^{2}$, A. Al-Sadek ${ }^{3}$ \\ ${ }^{1}$ Department of Orthopaedics and Traumatology, Belhoul European Hospital, Dubai, UAE \\ ${ }^{2}$ Faculty of Medicine, Trakia University, Stara Zagora, Bulgaria \\ ${ }^{3}$ Medical University, Sofia, Bulgaria
}

\begin{abstract}
PURPOSE: The aim of this study is to investigate the influence of Intermittent Pneumatic Compression (IPC) on the time from diagnosis to surgery in adult patients with internally fixated ankle fracture.

METHODS: The $1^{\text {st }}$ of February 2014 IPC was introduced in our department and implemented as a standard of care. IPC was prescribed 30 minutes 3 times daily until surgery. All patients with an unstable ankle fracture or lateral malleolar displacement more than $4 \mathrm{~mm}$ underwent standard surgical care.Intermittent pneumatic compression (IPC) is a system which enhances venous circulation and reduces edema. It consists of an air pump and a boot for the lower leg. In theory IPC compresses the edema and thereby preventing a surgical delay.

RESULTS:Patients managed with IPC had a statistically significant $50 \%$ reduction in time from presentation to surgery compared to those managed without, and had a reduced hospital stay. This resulted in a net saving for both patients and the hospital.

CONCLUSION: We conclude that foot pumps reduce the time to surgery and total hospital stay of patients requiring ankle Open Reduction and Internal Fixation (ORIF), and are cost effective.
\end{abstract}

Key words: Ankle Fractures, Swelling, Recovery Time, Intermittent Pneumatic Compression.

\section{INTRODUCTION}

When admitting patients with ankle fractures for surgical treatment the soft tissues are very important in terms of wound healing, infections, and surgical delay. If the soft tissues are too swollen the surgery is delayed and the patients typically lie with an elevated leg until the swelling has come down. This results in prolonged admission for the patients which also means a more expensive stay. Intermittent pneumatic compression (IPC), Figure 1. is a system which enhances venous circulation and reduces edema and. It consists of an air pump and a boot for the lower leg. In theory IPC compresses the edema and thereby preventing a surgical delay, pulmonary embolism and deep vein thrombosis. (1-5).

\section{MAERIALS AND METHODS}

The $1^{\text {st }}$ of February 2014 IPC, Figure 1. was introduced in our department and implemented as a standard of care. IPC was prescribed 30 minutes 3 times daily until surgery. All patients with an unstable ankle fracture or

*Correspondence to: Tabet Al-Sadek, M.D, Ph.D, Belhoul European Hospital- Dubai-UAE, Email: drthabet@abv.bg, Mobile: +971551503964 lateral malleolar displacement more than $4 \mathrm{~mm}$ underwent standard surgical care.

This study is a historical cohort comparison of the time to surgery 1 year prior and after the implementation of IPC. A search on admitted patients with ankle fracture diagnosis codes in the hospital database was conducted and data on age, gender and time for surgery was extracted. Health records were review for diagnosis verification and exclusion criteria's, whereas $\mathrm{x}$-ray images were reviewed for time of diagnosis and fracture classification.

Exclusion criteria's were:

- Age less than 16.

- External fixation.

- Conservative treatment.

- Multi-trauma i.e. more than 1 fracture.

- Tibial fracture.

- Transfer from other hospitals.

- Fractures from other hospitals.

- Fractures initially conservatively treated and the secondary displaced.

- Pathological fractures. 


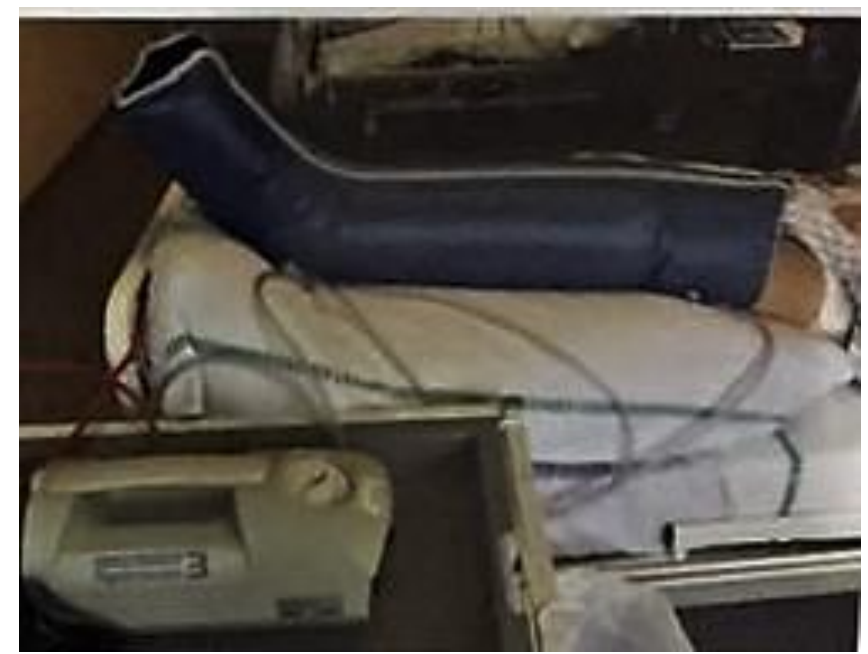

Figure 1. Intermittent pneumatic compression device.

(IPC)

\section{RESULTS}

The cohort consists of 40 patients and the Flowchart 1 shows the inclusion.

Prior to intermittent pneumatic compression (IPC) we had 20 patients from 01.02.201231.10.2013, 10 patients were excluded, 1 patient is treated with external fixation, 6 patients were treated conservatively, 1 patient had multi-trauma/ fracture, 1 patient with secondary displacement and 1 patient had a tibial fracture. So 10 patients were treated prior to IPC. 6 males and 4 females aged between 40-64 years old, types of fractures according to AO classifications were: (44 A1-A3) 2 patients, (44 B1-B3) 6 patients, (44 C1-C3) 2 patients. Surgical delay in median hours was (11-49).
After intermittent pneumatic compression (IPC) we had 20 patients from 01.02.201431.10.2015, 6 patients were excluded, 1 patient is treated with external fixation, 2 patients were treated conservatively, 1 patient had multi-trauma/ fracture, 1 patient with secondary displacement and 1 patient had a tibial fracture. So 14 patients were treated after IPC. 10 males and 4 females aged between 35 62 years old, types of fractures according to AO classifications were: (44 A1-A3) 2 patients, (44 B1-B3) 10 patients, (44 C1-C3) 2 patients. Surgical delay in median hours was (9-44).

After using the intermittent pneumatic compression (IPC), the inclusion number of patients has increased by 4 . Table 1 shows the results and there were no differences in gender or age in the two groups.

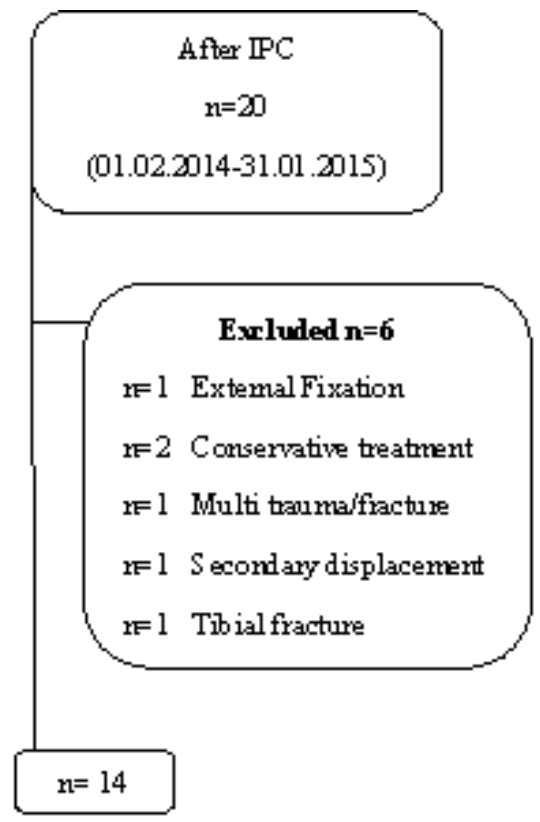

Flowchart 1. Results of the Cohort study. The flowchart shows the inclusion 
Table 1. The results and there were no differences in gender or age in the two groups.

\begin{tabular}{|c|c|c|}
\hline & w/out IPC & IPC \\
\hline Gender & \multicolumn{2}{|l|}{} \\
\hline Male & 6 & 10 \\
\hline Female & 4 & 4 \\
\hline Age & \multicolumn{2}{|l}{} \\
\hline Median (IQR) & $53(40-64)$ & $\begin{array}{c}51(35- \\
62)\end{array}$ \\
\hline AO & 2 & 2 \\
\hline 44 A1-A3 & 6 & 10 \\
\hline 44 B1-B3 & 2 & 2 \\
\hline 44 C1-C3 & \multicolumn{2}{|l}{} \\
\hline Surgical delay & 22(11-49) & $23(9-44)$ \\
\hline $\begin{array}{c}\text { Median hours } \\
\text { (IQR) }\end{array}$ & \multicolumn{2}{|l}{} \\
\hline
\end{tabular}

\section{DISCUSSION}

There was a difference in fracture classification with more complex fractures in the IPC group. The use of IPC separately or concomitantly, has become standard practice in the management of ankle fractures. These methods are directed at reducing edema based on principles affecting the lymphatics system, skeletal muscle contractions, local pressure gradients and the influence of gravity.

\section{CONCLUSION}

There does not seem to be any benefit from IPC on time to surgery in patients with acute ankle fracture in our setting. However, this may be due to an already short waiting time for surgery and IPC may have a beneficial effect in a different setting. Thus; preventing deep vein thrombosis and pulmonary embolism. (69).

\section{REFERENCE}

1. Virchow RLK. Die Verstopfung den Lungenarterie und ihre Flogen. Beitr ExperPath Physiol.; 2:1, 1846.

2. Virchow RLK. Phlogose und Thrombose im Gefäßsystem. Gesammelte Abhandlungen Zur Wißenschaftlischen Medizin. Frankfurt-am-Main: Von Meidinger Sohn \& Comp; 458-636, 1956.
3. Virchow RLK. Neuer Fall von t"dtlicher Embolie der Lungenarterien. Arch Pathol Anat.; 10:225-228, 1956.

4. Doran FSA, Drury M, Sivyer A. A simple way to combat the venous stasis which occurs in the lower limbs during surgical operations. Br J Surg.; 51:486-492, 1964.

5. Roberts VC, Sabri S, Beeley AH, et al. The effect of intermittently applied external pressure on the haemodynamics of the lower limb in man. Br J Surg.; 59:223-226, 1972.

6. Browse NL, Negus D. Prevention of postoperative leg vein thrombosis by electrical muscle stimulation: an evaluation with ${ }^{125}$ I-labelled fibrinogen. $\mathrm{Br} \quad \mathrm{Med}$ J.;3:615-618, 1970.

7. Nicolaides AN, Kakkar VV, Field ES, et al. Optimal electrical stimulus for prevention of deep vein thrombosis. Br Med J.; 3:756758, 1972.

8. Sabri S, Roberts VC, Cotton LT. Prevention of early postoperative deep vein thrombosis by intermittent compression of the leg during surgery. $\mathrm{Br}$ Med J.; 4:394-396, 1971.

9. Hills $\mathrm{NH}$, Pflug JJ, Jeyasingh $\mathrm{K}$, et al. Prevention of deep vein thrombosis by intermittent pneumatic compression of calf. Br Med J.; 1:131-135, 1972. 